\title{
Use of antibodies to carcinoembryonic antigen and human milk fat globule to distinguish carcinoma, mesothelioma, and reactive mesothelium
}

\author{
RJ MARSHALL, A HERBERT, SG BRAYE, DB JONES \\ From the University Department of Histopathology, Southampton General Hospital, Southampton
}

SUMMARY Antibodies raised against human milk fat globule (HMFG 1 and 2) and carcinoembryonic antigen were used in an immunoperoxidase technique to differentiate mesothelioma, carcinoma, and benign, reactive mesothelium. Sixteen mesotheliomas, 27 lung carcinomas, and 13 specimens of reactive mesothelium were examined. Staining for carcinoembryonic antigen was not seen in reactive mesothelium or mesothelioma but was present in 22 of 27 carcinomas. Mesothelioma and carcinoma usually stained with HMFG 1 and 2; reactive mesothelium did not. These three antibodies may help to distinguish carcinoma, mesothelioma, and reactive mesothelium.

Distinguishing mesothelioma from carcinoma is a well recognised problem.' Histochemistry and electron microscopy may help to make this distinction but do not always give a definitive answer. Antibodies to carcinoembryonic antigen (CEA) and keratin have been assessed with conflicting results. $^{2-7}$ It is equally difficult to distinguish benign from malignant mesothelium. Morphometry ${ }^{6}$ and the use of histiocytic markers in an immunoperoxidase technique ${ }^{8}$ have been advocated for this purpose.

Anti-CEA and HMFG 2 have been used previously to diagnose malignancy in cytological preparations of pleural fluids. ${ }^{910}$ Their usefulness in this respect depends on a knowledge of the staining behaviour of reactive mesothelium and of the pattern of staining of benign and malignant cells in histological preparations.

In this study we have evaluated three antibodies, anti-CEA and HMFG 1 and 2, to see if they would distinguish between carcinoma, mesothelioma, and benign, reactive mesothelium.

\section{Material and methods}

Tissue was examined from 16 mesotheliomas, 27 lung carcinomas, and 13 specimens in which reactive mesothelium was present. Tissue diagnosed as

Accepted for publication 24 July 1984 malignant mesothelioma was obtained from pleuro-pneumonectomy and pleurectomy specimens or from biopsies taken at thoracoscopy or thoracotomy (Table 1). Adequate material was available in all cases for definitive diagnosis to be made of biphasic (seven cases), epithelial (eight cases), or mesenchymal (one case) malignant mesothelioma using morphological criteria. All cases were stained with periodic acid Schiff after diastase digestion and were negative. The presence of acid mucopolysaccharide sensitive to hyaluronidase digestion was confirmed by staining with Alcian

Table 1 Malignant mesotheliomas

\begin{tabular}{llll}
\hline $\begin{array}{l}\text { Case } \\
\text { no }\end{array}$ & Type of specimen & $\begin{array}{l}\text { Histological } \\
\text { type }\end{array}$ & $\begin{array}{l}\text { Presence of } \\
\text { hyaluronidase } \\
\text { sensitive } \\
\text { mucopolysaccharide }\end{array}$ \\
\hline 1 & Pleuropneumonectomy & Epithelial & + \\
2 & Pleuropneumonectomy & Epithelial & - \\
3 & Pleuropneumonectomy & Mixed & + \\
4 & Pleurectomy & Epithelial & + \\
5 & Thoracotomy & Mixed & - \\
6 & Thoracoscopy & Mixed & + \\
7 & Thoracoscopy & Mixed & + \\
8 & Thoracoscopy & Mixed & - \\
9 & Thoracoscopy & Mixed & + \\
10 & Thoracoscopy & Mixed & + \\
11 & Thoracoscopy & Epithelial & - \\
12 & Thoracoscopy & Epithelial & + \\
13 & Thoracoscopy & Epithelial & + \\
14 & Thoracoscopy & Epithelial & - \\
15 & Thoracoscopy & Epithelial + \\
16 & Thoracoscopy & Mesenchymal - \\
\hline
\end{tabular}


blue at $\mathrm{pH} 1$ or 2.5 in the cytoplasm or acini of 10 of the 15 cases with an epithelial component.

The carcinomas were obtained from lobectomy, pneumonectomy, or lung biopsy specimens. Eight were squamous carcinomas, eight oat cell, four large cell, and seven adenocarcinomas, including one bronchioloalveolar cell carcinoma (Table 2).

Reactive mesothelium was examined in eight pleurae removed after pneumothorax (Table 2). Three pericardial and two pleural cases of mesothelial reaction to tumour infiltration were also examined.

Tissue was fixed in $10 \%$ neutral buffered formolsaline, routinely processed, and embedded in paraffin wax. Sections $(5 \mu \mathrm{m})$ were cut and stained with Mayer's haematoxylin and eosin. Further sections were examined with polyclonal rabbit antihuman CEA (Code No A115, Dakopatt Ab, Sweden), used at a dilution of $1 / 500$, using the method described by Mepham et al. " Two monoclonal antibodies, HMFG 1 and 2, (Seward Laboratory, London) were used at a dilution of $1 / 3$ in an indirect immunoperoxidase technique. These antibodies are directed against determinants in the membranes of human milk fat globules. ${ }^{12}$ They react with a variety of carcinomas and normal glandular epithelia..$^{13} 14$

Sections in which the first stage antibody was replaced by Tris buffered saline served as negative controls and showed no staining in any of the cases studied. Sections of breast carcinoma and colonic carcinoma were used as positive controls for HMFG 1 and 2 and CEA respectively.

\section{Results (Table 3)}

NORMAL BRONCHIAL AND ALVEOLAR EPITHELIUM

$H M F G 1$ and 2

Bronchial epithelium was present in 14 of the cases examined. HMFG 1 gave focal staining of the cilia and basal plate region of bronchial epithelial cells. HMFG 2 stained the epithelium of respiratory bronchioles with a similar pattern but was generally negative in the larger bronchioles and bronchi,

Table 2 Carcinomas and reactive mesothelium

\begin{tabular}{|c|c|}
\hline & $\begin{array}{l}\text { No of } \\
\text { specimens }\end{array}$ \\
\hline $\begin{array}{l}\text { Carcinoma } \\
\text { Squamous } \\
\text { Oat cell } \\
\text { Large cell } \\
\text { Adeno } \\
\text { Reactive } \\
\text { Pleurectomy following pneumothorax } \\
\text { Pericardectomy for malignant infiltration } \\
\text { Pleural biopsies in suspected malignant effusions }\end{array}$ & $\begin{array}{r}27 \\
8 \\
8 \\
4 \\
7 \\
13 \\
8 \\
3 \\
2\end{array}$ \\
\hline
\end{tabular}

Table 3 Results

\begin{tabular}{lrlll}
\hline & No & HMFG 1 & HMFG 2 & CEA \\
\hline $\begin{array}{l}\text { Mesotheliomas } \\
\text { Epithelial }\end{array}$ & 6 & + & + & - \\
Biphasic & 2 & + & - & - \\
Mesenchymal & 6 & + & + & - \\
Carcinomas & 1 & - & - & - \\
Squamous & 1 & - & - & - \\
& 7 & + & + & + \\
Oat cell & 1 & + & + & - \\
& 4 & + & + & + \\
& 2 & + & + & - \\
Large cell & 1 & - & + & - \\
Adeno & 1 & - & + & + \\
Reactive mesothelium & 3 & + & + & + \\
& 1 & - & + & + \\
& 10 & + & + & + \\
& 2 & + & - & - \\
& 1 & - & + & - \\
\hline
\end{tabular}

though no consistent difference in staining pattern was seen with these two antibodies. Bronchial reserve cells were prominent in seven cases and were stained with HMFG 1 and 2 (Fig. 1).

Normal alveolar epithelium was seen in 10 cases and in nine stained strongly with HMFG 2. HMFG 1 stained with varying intensity in five cases.

Reactive alveolar epithelium, present in 10 cases, stained strongly with HMFG 2 in nine cases and variably with HMFG 1 in seven cases.

\section{Anti-CEA}

The anti-CEA antibody stained bronchi and bronchioles with varying intensity in eight cases. Reserve cells were stained in three of the seven cases in a pattern similar to that seen with the HMFG antibodies. Normal alveolar epithelium stained strongly in nine of 10 cases, as with HMFG 2. The pattern of staining of reactive alveolar epithelium was variable and closely paralleled HMFG 1 .

\section{REACTIVE MESOTHELIUM}

\section{HMFG 1 and 2}

Ten of the 13 specimens of reactive mesothelium were negative with HMFG 1 and 2. One case stained with HMFG 2 and two cases with HMFG 1. Staining was very focal and seen on the free border of the cells.

Care was needed to distinguish reactive pneumocytes from mesothelium in excised bullous cysts, but identification was made easier by the presence of lung tissue. Pneumocytes then stained strongly with all three antibodies, while mesothelium was generally negative (Fig. 2).

\section{Anti-CEA}

This antibody did not stain any reactive mesothelial cells. 


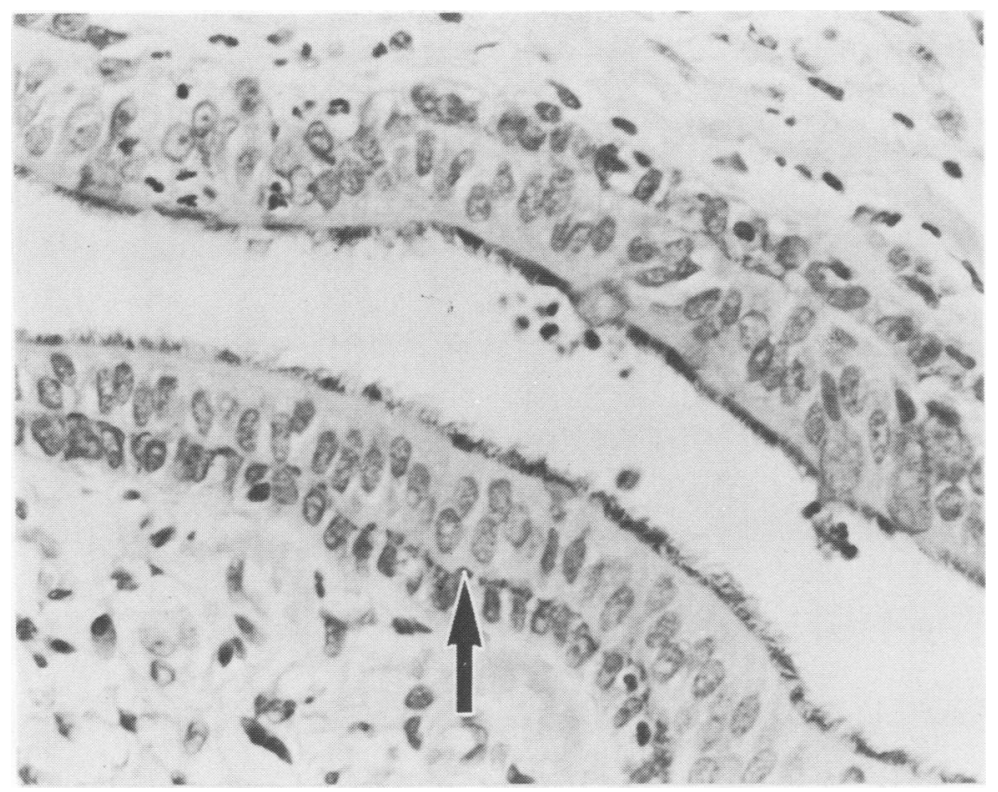

Fig. 1 Bronchus stained for HMFG 1. The cilia and basal plate region are positive. Reserve cells stain on the surface adjacent to the respiratory epithelium (arrow). PAP $\times 350$.

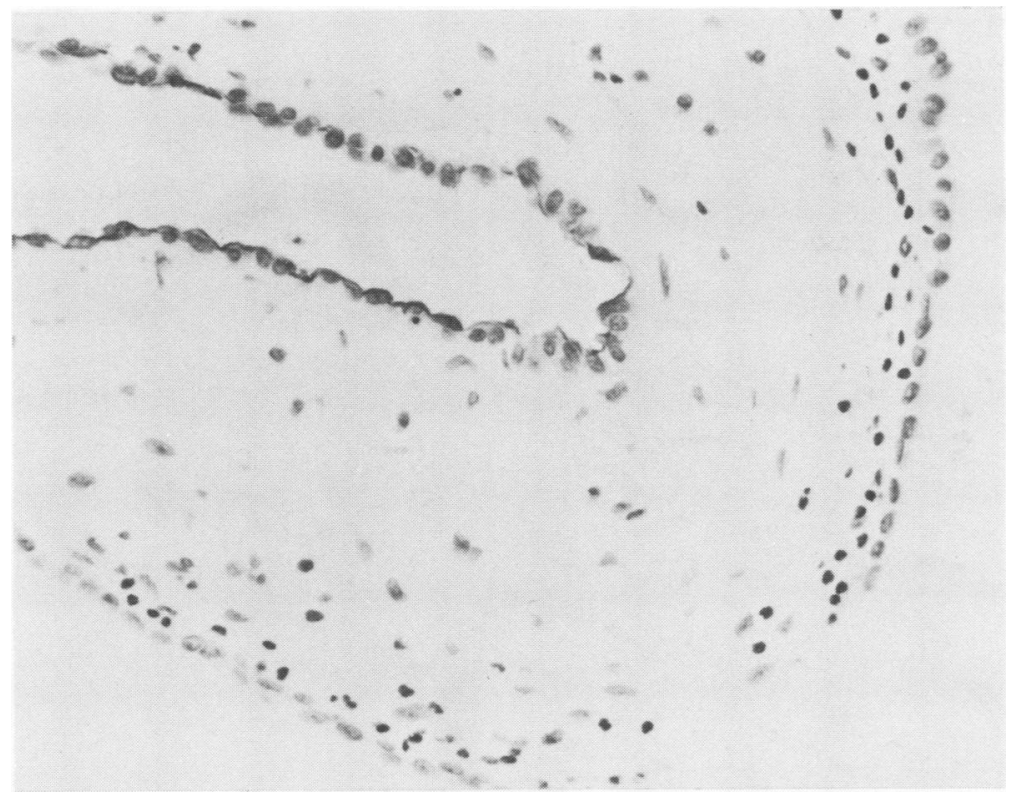

Fig. 2 Bullous cyst stained for HMFG 2. The respiratory epithelium on the inner surface is positive. Mesothelial cells do not stain. PAP $\times 250$. 


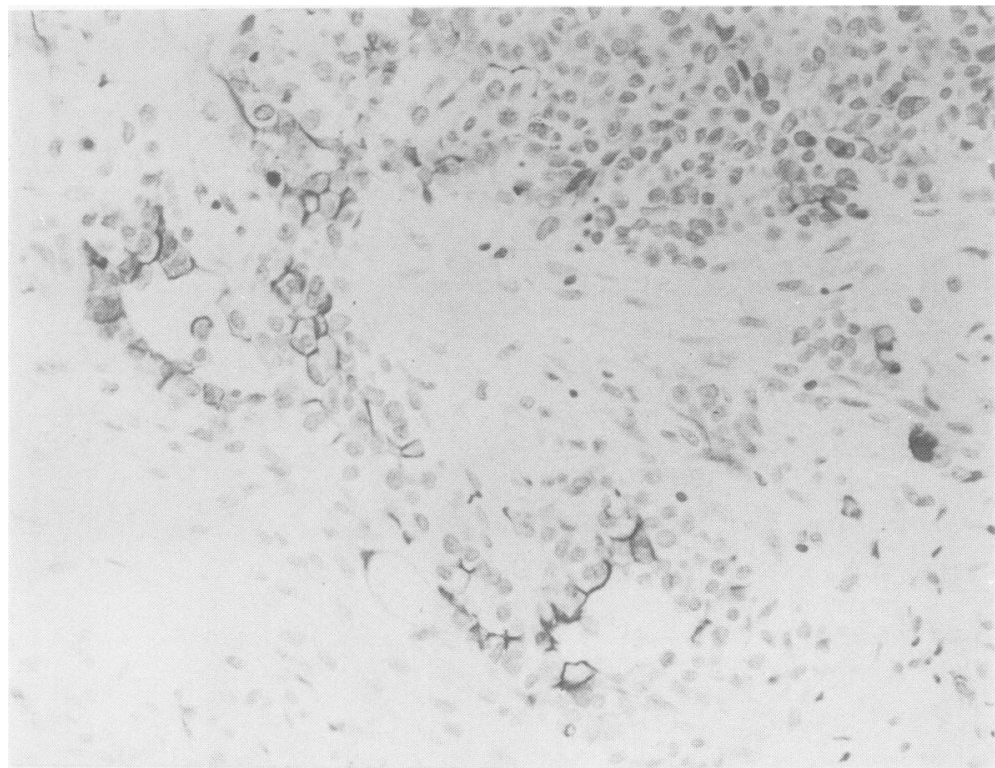

Fig. 3 Mesothelioma stained for HMFG 1. The solid clump of cells (top centre) stains weakly. Staining is denser where lumina are formed. PAP $\times 300$.

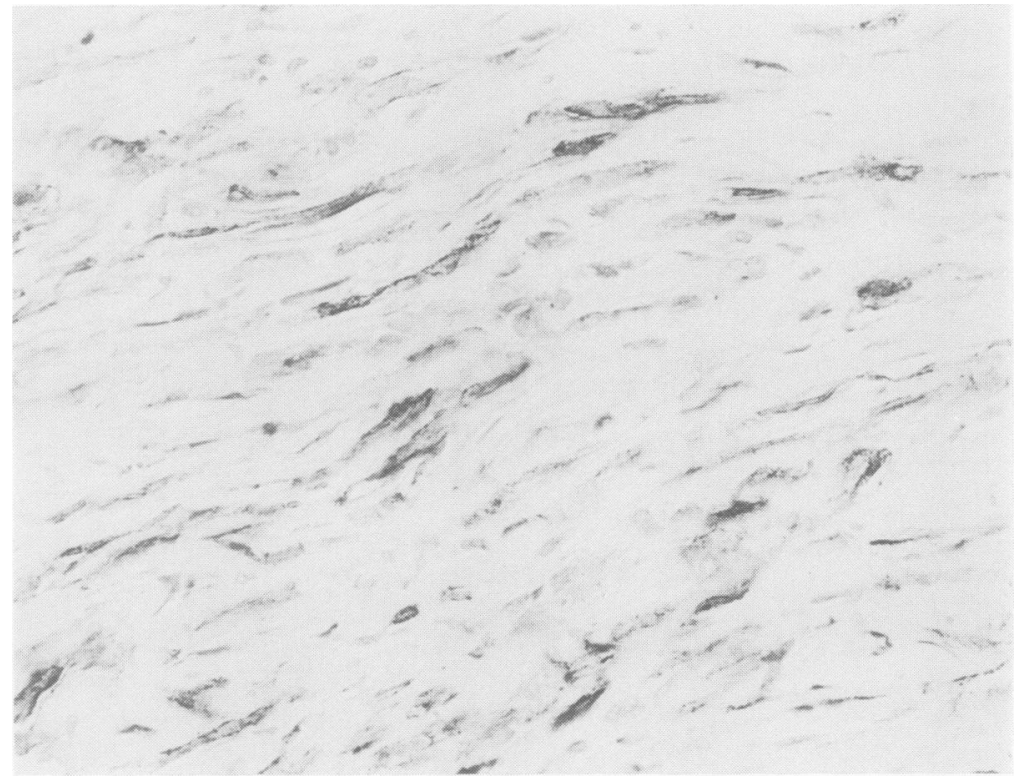

Fig. 4 Spindle cell element of a biphasic mesothelioma stained for HMFG 1. $P A P \times 400$. 

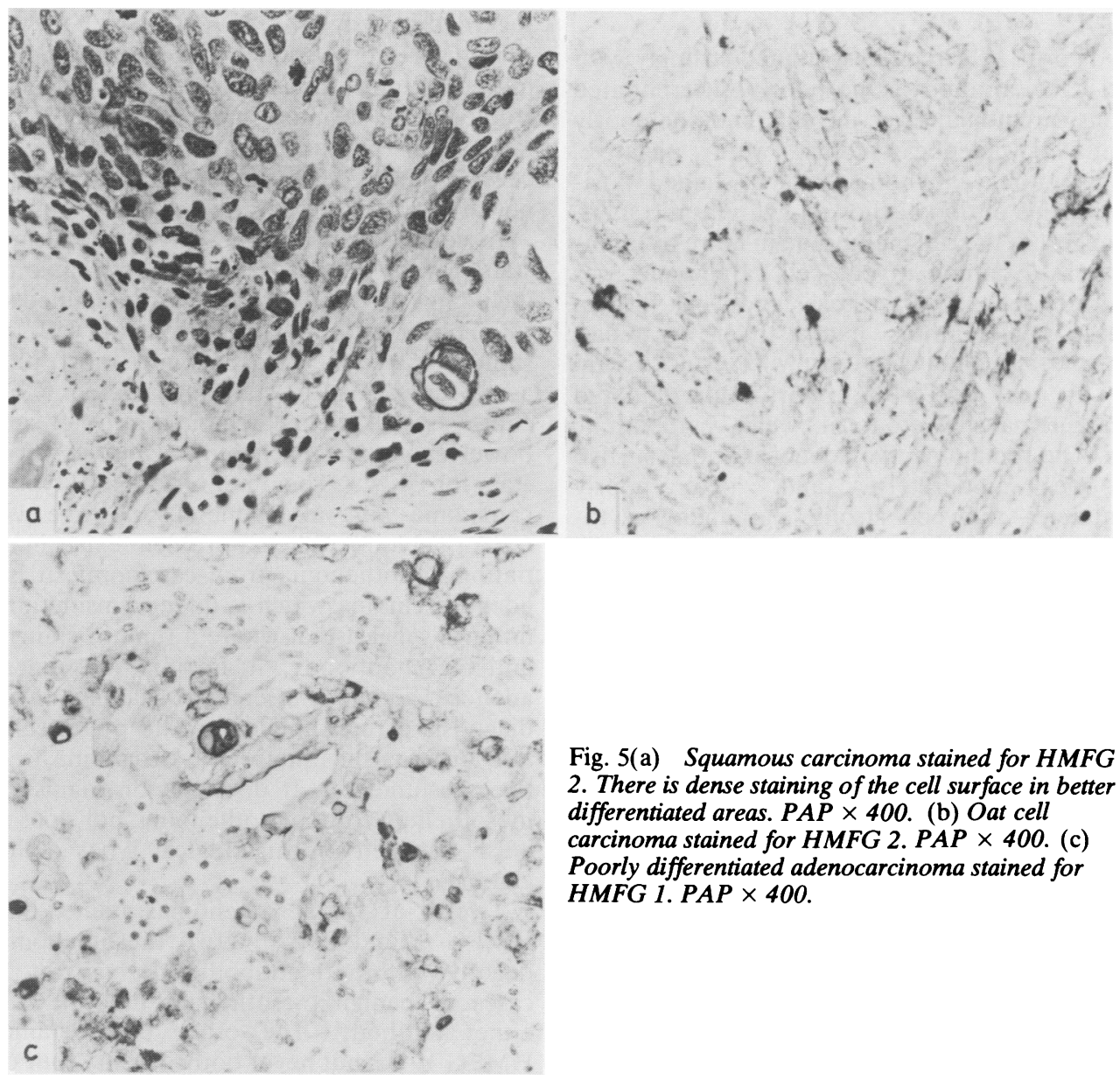

Fig. 5(a) Squamous carcinoma stained for $H M F G$ 2. There is dense staining of the cell surface in better differentiated areas. PAP $\times 400$. (b) Oat cell carcinoma stained for HMFG 2. PAP $\times 400$. (c) Poorly differentiated adenocarcinoma stained for HMFG 1. PAP $\times 400$

\section{MESOTHELIOMAS}

\section{HMFG 1 and 2}

Twelve of the 16 mesotheliomas were positive with HMFG 1 and 2 (Table 3). Staining was present in the cytoplasm of some cases but was more commonly present at the cell surface. Solid clumps of epithelial cells did not stain, but where clefts formed within the tumour, the luminal surfaces of the cells became strongly positive (Fig. 3). Three of the seven biphasic tumours showed strong, granular, cytoplasmic staining of the spindle cell element (Fig. 4).

\section{Anti-CEA}

Anti-CEA did not stain any of the cases of mesothelioma. Staining in occasional areas of necrosis was interpreted as negative.

\section{CARCINOMAS}

HMFG 1 and 2

All carcinomas were positive with HMFG 2, and 24 of 27 were positive with HMFG 1. (Table 3). All the squamous carcinomas showed focal staining with both antibodies. There were individual differences in the staining seen with each antibody but no constant pattern emerged. Staining was cytoplasmic with surface accentuation in more differentiated areas (Fig. 5a). Four oat cell carcinomas stained strongly with HMFG 1 and 2 (Fig. 5b).

Two did not stain with HMFG 1 and two others stained only weakly; these four carcinomas also stained weakly with HMFG 2. The four large cell anaplastic tumours showed strong staining with HMFG 2. Two of them showed similar staining with HMFG 1, one stained weakly with this antibody, and one not at all. All seven adenocarcinomas stained with both antibodies (Fig. 5c), staining strongly in all but one case. Variations in staining with the two antibodies were noted but showed no constant pattern. 


\section{Anti-CEA}

Twenty two of 27 carcinomas stained strongly with the anti-CEA antibody. One poorly differentiated squamous carcinoma, three oat cell, and one poorly differentiated adenocarcinoma were negative. Those squamous carcinomas which stained positively with this antibody showed cytoplasmic staining, strongest at the cell membrane in more differentiated areas. Staining in oat cell carcinomas was cytoplasmic, dense in three cases and weak in two. The large cell tumours had a focal, granular, intracytoplasmic staining pattern with surface accentuation in one case. One poorly differentiated adenocarcinoma showed focal, weak, cytoplasmic staining. The remaining five adenocarcinomas - two well, one moderately, and two poorly differentiated-showed strong, granular, cytoplasmic staining which was more pronounced at the luminal surface. The single bronchioloalveolar cell carcinoma stained strongly at the luminal surface of the cells. Areas of necrosis were commoner in carcinoma; staining in these areas was interpreted as negative.

\section{Discussion}

In this study we have used an immunoperoxidase technique to evaluate three antibodies - anti-CEA and HMFG 1 and 2-as aids to the diagnosis of mesothelioma, carcinoma, and reactive mesothelial proliferation.

CEA was absent in all mesotheliomas and cases of reactive mesothelium. Previous studies of mesothelioma employing this antibody have differed in their findings ${ }^{2-79}$ (Table 4$)$. When present, positive staining has been attributed to the increased sensitivity of the immunoperoxidase technique compared with immunofluorescence ${ }^{3}$ but the largest series, ${ }^{26}$ which examined a total of 77 cases with an immunoperoxidase technique, found them all negative. The most recent study' found positive staining in two cases. The source of their antibody to CEA differed from other studies and digestion with trypsin was carried out for $1 \mathrm{~h}$. Most other studies have omitted the use of trypsin. In our study tissues were trypsinised for 15-30 min;trypsinisation for $1 \mathrm{~h}$ tended to produce non-specific staining. Two other studies have found weakly positive staining in histological preparations. In one of these, ${ }^{5}$ the method of fixation differed from other studies and the other ${ }^{3}$ used an indirect immunoperoxidase technique as opposed to the peroxidase-antiperoxidase method. Clearly, differences in reagents and techniques may explain the differing findings but the detection of positive staining with antibodies to CEA in some studies means that the case for its absence cannot be regarded as proved.

Two previous studies have examined reactive mesothelium. In a histological study all three cases studied were negative. ${ }^{3}$ A further study examined cytological preparations of "active mesothelial cells" from 22 benign effusions, and again all were negative. ${ }^{9}$ Our results agree with these observations.

In contrast, all but one of the adenocarcinomas stained with the anti-CEA antibody; five of them, including two poorly differentiated, stained strongly. This observation is in agreement with previous studies, ${ }^{2-415}$ which have found most pulmonary adenocarcinomas to stain strongly for CEA. This contrasts with adenocarcinomas at other sites (large bowel carcinoma excluded), where fewer tend to stain for CEA. ${ }^{16}$ The other histological types of lung carcinoma were also generally positive with antiCEA (Table 3). When a problem exists in differentiating mesothelioma from carcinoma, it is usually adenocarcinoma which is under consideration. Our findings suggest that where a tumour stains with an anti-CEA antibody, it favours the diagnosis of adenocarcinoma. Absence of staining favours the diagnosis of mesothelioma. The presence of CEA also distinguishes metastatic carcinoma from reactive mesothelium. It does not distinguish reactive mesothelium from mesothelioma, nor does it distinguish between the histological types of lung carcinoma.

Twelve of 16 mesotheliomas stained with both HMFG 1 and 2. Only two mesotheliomas were negative with both antibodies. In contrast, 10 of 13 cases of benign mesothelium did not stain with either antibody. The other three stained with HMFG 1 or 2 but never both. Twenty four of the 27 carcinomas were positive with both antibodies; the other three stained with HMFG 2 but not HMFG 1 . Differences were noted in strength or pattern of staining in those tumours which did stain with both antibodies. Similar differences have been noted in breast carcinomas. ${ }^{17}$

Only a single case of mesothelioma, in a cytological preparation, has been studied previously, using HMFG 2 alone. ${ }^{9}$ Tumour cells were strongly posi-

Table 4 Results of previous studies of mesotheliomas using anti-carcinoembryonic antigen

\begin{tabular}{|c|c|c|c|}
\hline Study & $\begin{array}{l}\text { No of cases } \\
\text { examined }\end{array}$ & No positive & No negative \\
\hline $\begin{array}{l}\text { Whitaker et } a l^{2} \\
\text { Corson } e t a l^{3} \\
\text { Wang et } a l^{4} \\
\text { Said et } a l^{5} \\
\text { Kwee et } a l^{6} \\
\text { Holden et } a l^{7} \\
\text { Ghosh et } a l^{4} \\
\text { Total }\end{array}$ & $\begin{array}{r}40 \\
20 \\
12 \\
8 \\
37 \\
22 \\
1 \\
140\end{array}$ & $\begin{array}{r}0 \\
9 \\
0 \\
2 \\
0 \\
8 \\
1 \\
20\end{array}$ & $\begin{array}{r}40 \\
11 \\
12 \\
6 \\
37 \\
14 \\
0 \\
120\end{array}$ \\
\hline
\end{tabular}


tive. Previous histological studies of reactive mesothelium have not been performed with these antibodies, and cytological studies, using only HMFG 2, have differed in their findings. One reported benign mesothelium as negative ${ }^{10}$; another found weak staining in seven and strong staining in another seven of 22 cases. $^{9}$ This discrepancy was explained by differences in fixation and staining technique.

Our findings suggest that histological sections which do not stain with either antibody are more likely to be benign than malignant mesothelium. Positive staining with both antibodies is evidence in favour of malignancy. Positive staining with these antibodies does not help to differentiate mesothelioma from carcinoma; nor does the location of the staining within malignant cells help to make this distinction, since staining of the cell surface, particularly where it borders a lumen or cleft, is seen in both adenocarcinoma and mesothelioma.

Focal staining was commonly seen with all three antibodies. In two specimens of mesothelioma and four of carcinoma areas of positive staining were so widely separated that a small biopsy specimen might well have appeared negative. Clearly this affects the value of these antibodies when used on biopsy specimens.

Staining for keratin has been advocated to distinguish mesothelioma from adenocarcinoma of the lung $^{3}$ : the former is usually positive, and the latter negative. A combination of an anti-keratin and anti-CEA antibody would help greatly to distinguish between these two. Anti-CEA antibodies are of no use in differentiating reactive mesothelium from mesothelioma, while the monoclonal antibodies to milk fat globule do help to make this distinction. They generally indicate malignancy in the tissue we have examined but are not specific for either carcinoma or mesothelioma.

We thank the staff of the University Histology Department and Miss Margaret Harris for typing the manuscript.

\section{References}

' Kannerstein M, Churg J, McCaughey WTE. Asbestos and mesothelioma: a review. Pathol Ann 1978;13:81-129.

${ }^{2}$ Whitaker D, Shilkin KB. Carcinoembryonic antigen in tissue diagnosis of malignant mesothelioma. Lancet 1981;i:1369.

${ }^{3}$ Corson JM, Pinkus GS. Mesothelioma: Profile of keratin proteins and carcinoembryonic antigen. An immunoperoxidase study of 20 cases and comparison with pulmonary adenocarcinomas. Am J Pathol 1982;108:80-7.

${ }^{4}$ Wang N, Huang S, Gold P. Absence of carcinoembryonic antigen-like material in mesothelioma. An immunohistochemical differentiation from other lung cancers. Cancer 1979; 44:937-43.

${ }^{5}$ Said JW, Nash G, Tepper G, Banks-Schlegel S. Keratin proteins and carcinoembryonic antigen in lung carcinoma: An immunoperoxidase study of fifty-four cases, with ultrastructural correlations. Hum Pathol 1983; 14: 70-6.

' Kwee WS, Veldhuizen RW, Golding RP, et al. Histologic distinction between malignant mesothelioma, benign pleural lesion and carcinoma metastasis. Evaluation of the application of morphometry combined with histochemistry and immunostaining. Virchows Arch (Pathol Anat) 1982;397:287-99.

${ }^{7}$ Holden J, Churg A. Immunohistochemical staining for keratin and carcinoembryonic antigen in the diagnosis of malignant mesothelioma. Am J Surg Pathol 1984;8:277-9.

${ }^{8}$ Herbert A, Gallagher PJ. Interpretation of pleural biopsy specimens and aspirates with the immunoperoxidase technique. Thorax 1982;37:822-7.

' Ghosh AK, Spriggs AI, Taylor-Papadimitriou J, Mason DY. Immunocytochemical staining of cells in pleural and peritoneal effusions with a panel of monoclonal antibodies. J Clin Pathol 1983;36: 1154-64.

${ }^{10}$ Epenetos AA, Canti G, Taylor-Papadimitriou J, Curling M, Bodmer WF. Use of two epithelium-specific monoclonal antibodies for diagnosis of malignancy in serous effusions. Lancet 1982;ii: 1004-6.

"Mepham BL, Frater W, Michell BS. The use of proteolytic enzymes to improve immunoglobulin staining by the PAP technique. Histochem J 1979;11:345-58.

12 Taylor-Papadimitriou J, Peterson JA, Arklie J, Burchell J, Ceriani RL, Bodmer WF. Monoclonal antibodies to epithelium-specific components of the human milk fat globule membrane: production and reaction with cells in culture. Int $J$ Cancer 1981;28:17-21.

${ }^{13}$ Arklie J, Taylor-Papadimitriou J, Bodmer WF, Egan M, Millis R. Differentiation antigens expressed by epithelial cells in the lactating breast are also detectable in breast cancers. Int $J$ Cancer 1981;28:23-9.

14 Gatter KC, Abdulaziz Z, Beverley P, et al. Use of monoclonal antibodies for the histopathological diagnosis of human malignancy. J Clin Pathol 1982;35: 1253-67.

is Pascal RR, Mesa-Tejada R, Bennett SJ, Garces A, Fenoglio CM. Carcinoembryonic antigen: immunohistochemical identification in invasive and intraepithelial carcinomas of the lung. Arch Pathol Lab Med 1977;101:568-71.

${ }^{10}$ Goldenberg DM, Sharkey RM, Primus FJ. Immunocytochemical detection of carcinoembryonic antigen in conventional histopathology specimens. Cancer 1978;42:1546-53.

${ }^{17}$ Burchell J, Durbin H, Taylor-Papadimitriou J. Complexity of expression of antigenic determinants, recognized by monoclonal antibodies HMFG 1 and HMFG 2, in normal and malignant human mammary epithelial cells. $J$ Immunol (in press).

Requests for reprints to: Dr RJ Marshall, Department of Histopathology, Level E, South Block, Southampton General Hospital, Tremona Road, Southampton, 509 4XY, England. 